\title{
A fundamentação científica da proposta de seleção imigratória de Azevedo Amaral e as divergências sobre racismo entre mendelianos no Primeiro Congresso Brasileiro de Eugenia
}

\author{
The scientific grounding of the migratory selection proposal from \\ Azevedo Amaral and the disagreements about racism among \\ Mendelians in the First Brazilian Eugenics Congress
}

\author{
ANDERSON RICARDO CARLOS \\ Universidade Federal do ABC | UFABC \\ FERNANDA FRANZOLIN \\ Universidade Federal do ABC | UFABC \\ MÁRCIA HELENA ALVIM \\ Universidade Federal do ABC | UFABC
}

RESUMO Este artigo problematiza os divergentes posicionamentos sobre raça e etnia nas Atas e Trabalhos do Primeiro Congresso Brasileiro de Eugenia, associando-os às ideias de hereditariedade. Tal evento, ocorrido no Rio de Janeiro em 1929, foi considerado como a maior manifestação pública da eugenia no Brasil. Destacamos, por um lado, a fundamentação científica da proposta de seleção de imigração de Azevedo Amaral, e por outro lado, o posicionamento de outros eugenistas contrários à proposta, protagonizado por Edgard Roquette-Pinto. Portanto, este trabalho contribui por evidenciar a estreita e complexa influência do mendelismo na discussão de raça e etnia por eugenistas brasileiros.

Palavras-chave eugenia no Brasil - Azevedo Amaral - Edgard Roquette-Pinto - história da medicina - história da genética

\begin{abstract}
This paper problematizes divergent perspectives about race and ethnicity, associating them to heredity ideas, in the Meetings Minutes and Papers from the First Brazilian Eugenics Congress. This event occurred in Rio de Janeiro, in 1929, and was regarded as the greatest public manifestation of eugenics in Brazil. We highlight the scientific grounding of the migratory selection proposal created by Azevedo Amaral and, on the other hand, the arguments from eugenicists against the proposal, led by Edgar Roquette-Pinto. This paper contributes by evidencing the narrow, complex influence of Mendelianism in the discussion of race and ethnicity by the Brazilian eugenicists.
\end{abstract}

Keywords eugenics in Brazil - Azevedo Amaral - Edgard Roquette-Pinto - history of medicine - history of genetics 


\section{As Atas do Primeiro Congresso Brasileiro de Eugenia enquanto potencial fonte para discussões sobre o racismo científico}

Um dos fatores que estimularam a discussão sobre raça no âmbito humano foi o início da efervescência da problematização sobre as origens da humanidade dentro do imaginário social, no final do século XIX. Exemplos claros dessa efervescência na época, representada na literatura, estavam os relatos sobre "meninos-lobos" perdidos nas florestas do exótico Oriente, que despertavam muita curiosidade na população. Nessa discussão, duas vertentes foram significativas: a monogenista e a poligenista. A primeira, dominante até meados do século XIX, acreditava que a origem da humanidade era única. 0 ser humano, segundo essa versão mais próxima às escrituras bíblicas, teria se originado de uma fonte comum, sendo os diferentes tipos humanos apenas um produto "da maior degeneração ou perfeição do Éden". Classificava-se a humanidade em um gradiente, que ia do mais perfeito (próximo do Éden) ao menos perfeito (degenerado). A partir de meados do século XIX, com os crescentes questionamentos ao posicionamento da Igreja Católica frente às teorias evolutivas, a hipótese poligenista transformava-se em uma outra alternativa. Nela, os autores acreditavam na existência de vários centros de criação para a origem do ser humano, que corresponderiam às diferenças raciais observadas, colocando fim aos elos entre todos os homens. A versão poligenista fortaleceu uma interpretação biológica na investigação dos comportamentos humanos, contribuindo no fortalecimento do determinismo biológico. Esse tipo de viés foi simultaneamente encorajado pelo nascimento da frenologia e da antropometria, áreas científicas que associavam a interpretação da capacidade humana a partir do tamanho e proporção do cérebro de diferentes etnias .

Assim, é interessante notar que conceitos como o monogenismo e o poligenismo estavam incluídos na área da antropologia física, a qual se desenvolveu como um ramo das ciências biológicas. Tal área se esforçava em lidar com as medições craniométricas para análise dos povos ou mesmo observações de hábitos, muito parecidos com 0 que atualmente se fazem no ramo das ciências biológicas, analisando comportamento de animais. Por isso, quando se avalia o conteúdo de importantes museus no século XIX, encontra-se, majoritariamente, a seção da antropologia muito próxima à da zoologia. Assim em acervos como o do Museu Nacional no Rio de Janeiro, propunha-se a análise de outros povos não-brancos, como os povos indígenas, como se representassem outra espécie, uma forma de animalização dos seres humanos que não fossem brancos 2 . Alguns adeptos da interpretação poligenista, como o médico e antropólogo francês Paul Broca (1822-1880), nome conhecido da "Escola Craniológica Francesa", admitia a tese da "imutabilidade das raças". Para ele, era possível traçar paralelos entre o exemplo da não fertilidade da mula e uma então verossímil esterilidade de mestiços. Em uma de suas análises craniométricas, Broca interpretou seus dados de uma forma hierarquizante. Para ele, o rosto projetado para a frente, a cor da pele mais negra, o cabelo crespo seriam fatores inerentemente relacionados à inferioridade intelectual e social ${ }^{3}, 4, \underline{5}$.

Tais discussões advindas no século XIX serviram como um dos fomentos para a formação de movimentos eugênicos ao redor do mundo, que buscavam a melhora da raça humana a partir das leis da hereditariedade. Mais tardiamente, tais movimentos também se desenvolveram no Brasil. Na literatura científica nacional, a vinda do termo "eugenia" se caracterizou como emblema de modernidade cultural, associada a um conhecimento científico que designava uma versão mais atualizada da ciência moderna da época ${ }^{6}$.

Segundo Souza, a introdução do termo simbolizou a preocupação das elites políticas e intelectuais com o precário estado de saúde da população, da situação sanitária e da composição racial do Brasil, além da própria preocupação inerente ao posicionamento brasileiro no âmbito internacional. Nesse sentido, discutir sobre a eugenia em nosso país exprimia preocupações sobre evolução, progresso e civilização. Encontros de cientistas - a maioria com formação em medicina -- se iniciaram, a partir de então, também em São Paulo com vista a discutir a nova ciência da eugenia explicitada por Francis Galton. Durante a década de 1910, a medicina, a higiene e a eugenia passavam a ser utilizadas como uma agregação de ferramentas civilizadoras e salvacionistas, caracterizadas como práticas científicas em busca da reforma social e da construção de uma nova nacionalidade ${ }^{?}$.

Apesar da remanescente presença de ideias sobre a herança de caracteres adquiridos na eugenia brasileira (descritas na historiografia como os neolamarckistas, que pressupunham que fatores ambientais, a exemplo de doenças, 
condições morais e sociais, influenciavam a descendência), havia uma ampla corrente eugênica mendeliana no Brasil. Tal perspectiva era representada, sobretudo, pelas figuras de Edgard Roquette-Pinto (1884-1954) e Octavio Domingues (1897-1972). A linha mendeliana se pautava na póstuma adoção das ideias de Mendel em 1900, conceito científico que reivindicava que os fatores hereditários estavam subordinados aos fatores internos, que recentemente atribuímos aos cromossomos e, consequentemente, ao DNA ${ }^{8,9}$.

Stefano analisou as obras do mendeliano Octavio Domingues e concluiu que o eugenista brasileiro acreditava que o melhoramento da espécie humana só ocorreria a partir da modificação dos genótipos dos indivíduos. Assim, dentro de um contexto em que se pensava e se defendia um "branqueamento" da raça brasileira, Domingues adotou um posicionamento alternativo a muitos de seus companheiros da ciência eugênica, uma vez que o centro das atenções não seria mais o fenótipo, ou seja, a cor de pele ${ }^{10}$.

Ao lado das discussões sobre hereditariedade, a conjuntura brasileira do início do século XX, caracterizava-se no crescimento do autoritarismo, expresso pelo contexto médico do higienismo-sanitarismo ${ }^{11}$, 12 e da emergência política do tenentismo ${ }^{13,14}, 15$, permitindo o florescimento do movimento eugênico brasileiro. Nesse contexto, a Academia Nacional de Medicina iniciou a divulgar que realizaria um congresso nacional sobre eugenia, como parte integrante das comemorações que marcariam os 100 anos da instituição, cuja fundação aconteceu em 1829. 0 anúncio do Congresso, pela Academia de Medicina, contribuiria, por um lado, para revalidar o interesse e a consolidação da eugenia como uma das principais áreas científicas tratadas pelos intelectuais brasileiros e, por outro, para definir os novos rumos que o movimento eugênico trilharia durante a próxima década de 1930ํㅗ․ Portanto, em julho de 1929 aconteceu uma das consideradas mais relevantes manifestações públicas da eugenia em território nacional: o Primeiro Congresso Brasileiro de Eugenia (PCBE).

Segundo Stepan, os temas do congresso foram variados, incluindo:

(...) casamento e eugenia, educação eugênica, a proteção da nacionalidade, tipos raciais e eugenia, a importância de arquivos genealógicos, imigração japonesa, campanhas antivenéreas, intoxicantes e eugenia, o tratamento de doenças mentais, educação sexual, a proteção da infância e das mães. Os participantes (do congresso) passaram por várias resoluções, a mais controversa sendo uma chamada para uma lei de imigração nacional para restringir entrada no Brasil daqueles indivíduos considerados eugenicamente inapropriados com base em algum tipo de teste médico ${ }^{17}$.

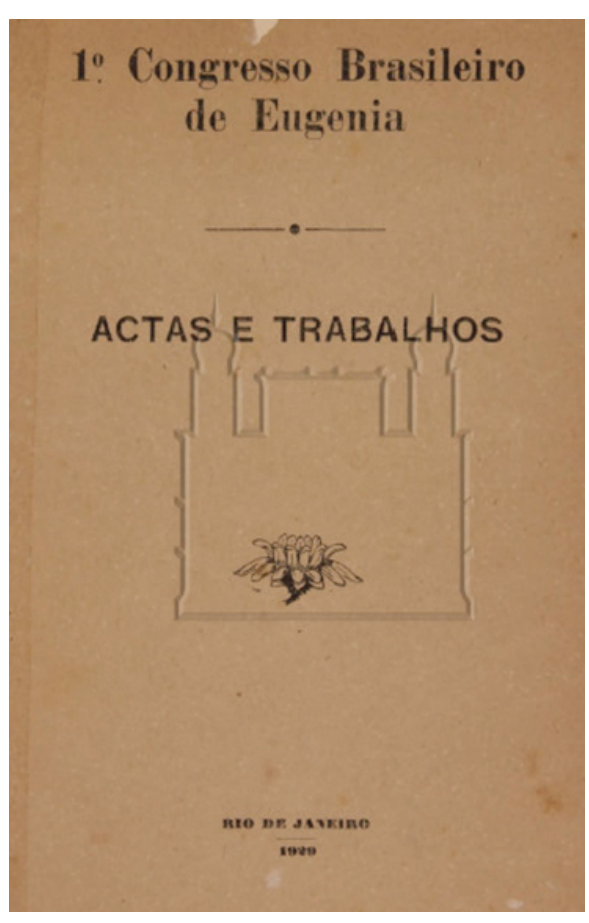

Considerando o movimento eugênico brasileiro e, sobretudo, a análise dos registros do Primeiro Congresso Brasileiro de Eugenia (Figura 1), muitas reflexões sobre o racismo podem ser pautadas. Alguns aspectos da eugenia estavam intrinsecamente relacionados à política de identidade nacional, que se baseava, como um de seus fatores, na questão de raça: ponto mais discutido pela literatura científica atual, vindo o racismo diretamente ao imaginário popular quando se trata do tema da eugenia. Independentemente da corrente teórica, muitas perspectivas da eugenia provaram ser interpretadas flexivelmente em ideologias racistas $\frac{18}{}$.

Figura 1: Primeira página das atas e trabalhos do Primeiro Congresso Brasileiro de Eugenia, publicado no Rio de Janeiro em 1929

Fonte: PCBE (1929) 
A identidade dos mulatos e negros no Brasil nesta época era discutida como exequível a um processo de transformação e melhora racial, uma vez que norte-americanos e europeus faziam uma avaliação negativa sobre a miscigenação e se considerava que o Brasil, de alguma maneira, também deveria se alinhar a tal perspectiva ${ }^{19}$. Segundo Silva e Fonseca, até mesmo em grandes periódicos médicos brasileiros, como em 0 Brasil Médico, muito popular na primeira metade do século XX, a escolha e divulgação das imagens traziam um racismo explícito, mesmo que o periódico se comprometesse ao discurso oficial de nação racialmente unida. Fotografias de pacientes trazidas em 0 Brasil Médico para a análise de enfermidades, em sua maioria, traziam uma infinidade de corpos negros, os quais normalmente apareciam sem tarjas nos rostos e nus, diferentemente da minoritária parcela de imagens de pacientes brancos. Desse modo, se cristalizava um tipo de olhar que representava simbolicamente a raça negra associada à doença e à degeneração. Tais subsídios ofereciam elementos formadores de hierarquias sociais com base em uma perspectiva biológica, a qual pregava a intervenção na sociedade e nos corpos como forma de mecanismos de defesa da nação brasileira ${ }^{20}$.

A partir desse panorama, propomos aqui nesta pesquisa uma reflexão sobre um documento histórico que é considerado por historiadores, como Stepan, uma das maiores manifestações públicas da eugenia no Brasil: o volume I das Atas e Trabalhos do Primeiro Congresso Brasileiro de Eugenia (PCBE), organizado no Rio de Janeiro, em 1929. Almejamos aqui problematizar as divergentes ideias de raça e etnia associando-as com suas concepções científicas sobre hereditariedade, na perspectiva mendeliana, através da análise dessa fonte histórica. Souza salienta a relevância das Atas e Trabalhos do Primeiro Congresso Brasileiro de Eugenia, uma vez que o material simboliza um evento científico de importância nacional, não unicamente para o movimento dos eugenistas brasileiros, mas para a própria história intelectual brasileira. Este autor também indica a escassez de trabalhos científicos específicos sobre o PCBE, incentivando estudos sobre 0 documentoำ ${ }^{21}$ Além disso, notabilizamos a relevância de utilizar esse documento como fonte documental principal deste trabalho por alguns dos temas discutidos no Congresso repercutirem, inclusive, em desdobramentos científicos e políticos significativos nos anos seguintes. Entre eles, pode-se citar discussões como seleção imigratória e políticas públicas médicas durante a posterior Era Vargas, na década de 193022, 23 . A análise dessa fonte primária visa evidenciar discussões científicas e propostas para as políticas públicas, como seleção de imigração e educação, diretamente da voz dos eugenistas brasileiros naquele tempo.

Os índices do primeiro volume do Congresso incluem: convite-circular, regimento interno, atas do Congresso de Eugenia, conferências de 5 cientistas e apresentação do trabalho de 20 cientistas, somando cerca de 370 páginas. Dessa maneira, abordaremos os trabalhos de eugenistas que possibilitem a discussão sobre raça objetivada por nossa pesquisa, dentre os quais consideramos mais oportunos os materiais escritos por Azevedo Amaral e Edgard Roquette-Pinto. Contudo, não estaremos limitados à análise exclusiva destes trabalhos, dado que citaremos argumentações tangenciais ao tema em outros estudos apresentados por mendelianos, a exemplo de Fróes da Fonseca e André Dreyfus. É importante destacar que nos limitaremos à análise da perspectiva mendeliana, uma vez que os trabalhos que discutem raça no Congresso são expressos em conformidade com essa perspectiva.

\section{A fundamentação científica do trabalho de Azevedo Amaral no PCBE: as relações entre a proposta eugênica para imigração e o determinismo genético}

Ideias referentes e massivamente discutidas na Europa durante o século XIX, ecoavam nas propostas eugênicas dos brasileiros na década de 1920. No Primeiro Congresso Brasileiro de Eugenia, em 1929, o médico e jornalista político brasileiro A. J. Azevedo Amaral (1881-1942) introduz seu trabalho 0 problema eugênico da imigração ressaltando sua crença na origem poligenista da humanidade, ou seja, no qual havia vários centros de criação para a origem do ser humano, negando o elo entre os povos. Como já exposto aqui, tal crença poligenista poderia conduzir às ideias que se convertiam, cada vez mais, em um determinismo biológico. 0 médico argumentava que diferenças biológicas entre 
povos denotavam profundas diferenças quanto à peculiaridade da psicologia coletiva das nações e à intangibilidade do plasma germinativo, as quais poderiam ser utilizadas para classificar tais povos como diferentes espécies zoológicas e como tipos inferiores de civilização $\underline{24}$.

À época, seu trabalho foi colocado como o último documentado no Primeiro Congresso Brasileiro de Eugenia e trouxe a maior controvérsia dentre todos os trabalhos do Congresso, em função do acalorado debate que causou, o qual foi descrito minuciosamente nas Atas do evento. No dia 2 de julho de 1929, no Anfiteatro de Química da Faculdade de Medicina, no Rio de Janeiro, Azevedo Amaral proferiu sua palestra, gerando polêmica sobretudo devido à sua veemente defesa da proibição à entrada de imigrantes não brancos no território brasileiro ${ }^{25}$.

Sustentando suas ideias pela perspectiva poligenista, Azevedo Amaral reconhece a dificuldade do diagnóstico da complexa formação étnica brasileira a partir de elementos suficientemente definidos, visando à medidas eugênicas práticas. Portanto, para ele, a questão primordial não seria a seleção de grupos étnicos, mas sim: “(...) a formação de uma raça nacional, isto é, a criação de um tipo étnico novo por meio da seleção sistemática dos elementos de elite encontrados na própria população nacional e dos que forem importados de outras terras"르. É sintomático, nesse período, a preocupação dos eugenistas em fazer coincidir os termos "raça" e "nação", considerando que o progresso estaria intrinsecamente relacionado a sua mútua fortificação ${ }^{27}$. Paradoxalmente, autores descrevem que Azevedo Amaral buscava negar qualquer projeto do tipo fascista e totalitário. Considerado importante pensador autoritário e admirador do Estado Novo de Getúlio Vargas - período político que viria nos anos seguintes ao Congresso - o jornalista não acreditava na liberal-democracia para o Brasil, apenas para países anglo-saxões. Assim, ele era visto como um pensador do tipo bonapartista, basicamente caracterizado por uma política autoritária, porém, rejeitando extremismos tanto da esquerda quanto da direita르․

Para sustentar seus argumentos sobre a proibição da entrada de imigrantes não brancos, Azevedo Amaral mostra ciência de que os estudos biológicos mais recentes de sua época não são compatíveis com a herança de caracteres adquiridos, citando, inclusive, nomes importantes, como os estudos de Weismann²9. Em um trecho específico, ele é bem enfático ao questionamento da herança de caracteres adquiridos. Ele a diferencia se aproximando de argumentos da perspectiva mendeliana, a qual ele caracteriza como "crente na permanência dos caracteres hereditários". Apesar de caracterizar seu trabalho de um cunho mais sociológico, o autor não deixa de destacá-lo como coerente com os novos conhecimentos da área das ciências biológicas:

Cremos que, no estado atual dos conhecimentos biológicos, pode-se com desassombro aceitar, como preferível a ideia da permanência dos caracteres hereditários e da evolução por um exclusivo processo seletivo. Mas, apresentando esta tese a uma secção sociológica de um congresso de eugenia, temos o dever de procurar, principalmente, nos fatos e nos ensinamentos da sociologia as demonstrações por ela abundantemente fornecidas em apoio da doutrina biológica que contesta a influência modificadora do meio sobre a raça, negando a transmissibilidade dos caracteres adquiridos ${ }^{30}$.

Nesse sentido, Azevedo Amaral afirma que suas teorias de imigração de caráter excludente estavam de acordo com recentes pesquisas em hereditariedade, uma vez que alguns povos seriam dotados de uma "fatalidade hereditária" que carregavam no plasma germinativo ${ }^{31}$. Citando pesquisas de Popenoe e Johnson (no trabalho Applied Eugenics) e S. J. Holmes (The Trend of the Race), ele enfatiza a crença na permanência de caracteres hereditários para fatores intelectuais e morais, levando a um determinismo genético. É importante ressaltar que, apesar de Azevedo Amaral não discutir conceitos mendelianos ou citar as leis de Mendel, suas referências científicas eram crentes no mendelismo. 0 livro citado The Trend of the Race, publicado em 1921, foi produto de um curso de palestras sobre eugenia, escrito por Samuel J. Holmes, professor de Zoologia da Universidade da Califórnia. Crítico da herança de caracteres adquiridos, desde a introdução de seu livro, Holmes descreveu em um quadro as características dominantes e recessivas para os traços da hereditariedade humana, citando importantes eugenistas americanos, como Charles Davenport $\frac{32}{2}$. Além disso, Popenoe e Johnson, mencionam em seu trabalho Applied Eugenics, que, considerando os dados apresentados 
na época, a herança de caracteres adquiridos não cobriria mais de duas gerações e tinha pouco ou nenhum valor como evidência científica ${ }^{33}$. Assim, apoiado nos dados de eugenistas mendelianos, Azevedo Amaral constrói sua argumentação científica visando propor medidas práticas para as políticas públicas brasileiras.

Dessa maneira, o médico e jornalista acreditava que algumas etnias seriam biologicamente dotadas de menor capacidade intelectual e mais propensas à imoralidade - as quais sua entrada, definida pelo autor como imigração promíscua, deveria ser desencorajada em função de poderem degenerar moral e intelectualmente a nação brasileira com sua herança biológica empobrecida ${ }^{34}$.

Naquela época, entre o fim do século XIX e início do XX, as elites brasileiras temiam os negros e mestiços, estando no inconsciente de muitas Escolas de Medicina que algumas doenças teriam vindo da África com os escravos e os problemas de higiene foram diretamente relacionados às raças mestiças e negras ${ }^{35}$. Eugenistas brasileiros percebiam os homens das camadas pobres como inerentes de grande irresponsabilidade sexual e mais prováveis de serem infectados com doenças, um dos fatores que justificava a crença de Azevedo Amaral na herança hereditária moralmente degenerada das camadas populares ${ }^{36}$. Na década de 1920, a avaliação das condições sociais das camadas populares permitia, aos eugenistas, uma visão subjetiva que assumia uma interpretação de degeneração moral da população. Por outro lado, ressalta-se que as condições das camadas populares - majoritariamente composta por negros e mestiços eram de semiescravidão. Não havia contrato de trabalho, não havia direito a descanso semanal remunerado ou licença para tratamento de saúde. As empresas funcionavam em prédios adaptados, sem condições de higiene e segurança, gerando frequentes acidentes. Além disso, os velhos problemas de abastecimento de água, de saneamento e higiene assolavam o período com violentos surtos e epidemias ${ }^{37}$.

Acima de tudo, ressalta-se que a relação entre o conceito de inteligência e moralidade era um dos temas prediletos dos eugenistas. Entre suas referências, apoiavam-se nos estudos do psicólogo americano E. L. Thornidike (década de 1940, Universidade de Colúmbia) que buscavam encontrar um coeficiente numérico entre inteligência e moralidade. Outro bom exemplo refere-se ao americano H. H. Goddard. Em seus estudos na década de 1920, Goddard ampliou a esfera dos efeitos sociais, os quais poderiam ser atribuídos às diferenças de inteligência inata transmitida hereditariamente, incluindo, praticamente, todos os aspectos do comportamento humano. 0 psicólogo dispõe a maior parte dos comportamentos considerados por ele indesejáveis a uma deficiência mental hereditária dos infratores. Portanto, seus problemas não seriam causados apenas pela falta de intelectualidade, mas pela combinação de deficiência mental e imoralidade ${ }^{38}$.

Além disso, a tentativa de proibição da entrada de raças não brancas no Brasil não era um pensamento isolado de Azevedo Amaral, dado que havia uma reivindicação engrossada por acadêmicos da Faculdade de Direito de São Paulo, elogiando leis de segregação de raças aplicadas na África do Sul e nos EUA, as quais buscavam impedir a entrada de imigrantes asiáticos e africanos no país $\frac{39}{}$.

Em 1925, em artigo publicado nos Arquivos Brasileiros de Higiene Mental, o médico eugenista Juliano Moreira alertava sobre 0 grande número de imigrantes considerados indesejáveis, os quais diariamente adentravam no Brasil sem qualquer mecanismo de controle de fiscalização. Para ele, controlar tal imigração seria mais importante que meIhorar condições de saúde física e mental ${ }^{40}$. Muitos eugenistas, como o médico e professor Miguel Couto, presidente do Primeiro Congresso Brasileiro de Eugenia, eram especialmente contrários a entrada de japoneses no Brasil, maior grupo étnico a emigrar para o Brasil durante a década de 1920. Couto e outros eugenistas acusavam os japoneses de criarem um "mosaico racial", além de introduzirem novas doenças para o país e, juntamente com os judeus, eram considerados elementos "não assimiláveis" ao corpo político¹. Mesmo fora do âmbito científico, ainda na década de 1920, alguns deputados propuseram na Câmara Federal projetos de lei que buscavam proibir a entrada de imigrantes negros e amarelos no país. Nesse sentido, tal década foi marcada por constantes discordâncias entre lideranças intelectuais, representadas nas figuras de literatos, políticos e cientistas, sobre as políticas de seleção imigratória ${ }^{42}$.

Em seu trabalho no Congresso, Azevedo Amaral sugere a criação de critérios próprios para a entrada de imigrantes no Brasil que fossem baseados nas discussões do Quota Act, adotado nos Estados Unidos em 1921, visando a não alterar as proporções da mistura de elementos étnicos fundamentais para seu ideal de nação ${ }^{43}$. Tal sugestão também 
era reforçada por outros eugenistas, como Juliano Moreira que argumentava, na mencionada publicação de 1925, que o governo brasileiro deveria se atentar ao resultado dos malefícios provindos da facilidade de entrada no país, a exemplo do que já vinha ocorrendo em países como os Estados Unidos e a Inglaterra. Para Moreira, grande parte dos problemas sociais, como a delinquência, a loucura, a criminalidade e o alcoolismo, estariam inevitavelmente associados à entrada desses imigrantes "degenerados" no país ${ }^{44}$. Da mesma forma que a lei americana, Amaral propõe no Congresso que a imigração no país seja exclusivamente branca, justificando:

Embora a nossa formação nacional tenha sido em grande parte conseguida pela contribuição de um vasto elemento africano - o índio representou papel relativamente secundário na composição étnica brasileira - seria inadmissível que consentíssemos na entrada de imigrantes de raça negra. A nossa finalidade nacional orienta-se no sentido da elaboração de uma civilização do tipo europeu e para atingir esse objetivo temos a necessidade de não agravar, com o acréscimo de elementos étnicos alheios à raça branca, a desvantajosa posição em que nos encontramos no continente, em relação a outros povos mais imunes do que nós da mistura de raças coloridas ${ }^{45}$.

Em seguida, Azevedo Amaral disserta sobre o mérito de quais linhagens europeias seriam vantajosas para a entrada no Brasil, dentre as quais destaca a preferência pelos países escandinavos (Noruega, Suécia e Dinamarca) e pela Alemanha, argumentando a necessidade de discriminá-los de outros países europeus, como países ibéricos, Itália, Polônia e Rússia. 0 médico brasileiro julgava esses últimos países como estando em declínio intelectual, sobretudo considerando sua preocupação em relação à suposta "fatalidade hereditária" que carregavam, baseado nos estudos de Clarence Yoakum, Army Mental Tests, e de Robert M. Yerkes (1876-1956) - que trabalhou em conjunto com o já citado H. H. Goddard na década de 19106. À vista disso, o eugenista brasileiro discutia que a situação contemporânea dos anos 1920 era diferente de anos atrás, nos quais o único critério para a política imigratória era o incentivo para entrada de povos italianos e ibéricos, dado apenas à implícita preocupação com o branqueamento da população brasileira ${ }^{47}$.

Na realidade, para compreendermos o pensamento de A. Amaral é importante entendermos o que o trabalho por ele citado propunha e sua conjuntura. Segundo Gould (2014), nas primeiras décadas do século XX, Robert M. Yerkes era um reconhecido cientista americano, tornando-se professor da Universidade de Harvard a partir de 1920. Sua especialidade durante esse período, a psicologia, era considerada negativamente como uma "ciência branda" e, para outros, era desconhecida, sendo muitas vezes chamada de pseudociência. Nesse sentido, Yerkes almejava consolidar a posição científica da psicologia, evidenciando que ela poderia ser uma ciência tão rigorosa quanto a física. Para isso um fator seria fundamental: quantificação e números. Dentro das subáreas da psicologia, Yerkes escolheu um ponto que parecia promissor: os testes mentais, grande alvo de interesse da ciência na época, os quais, para ele, poderiam dar à psicologia o mais alto status científico e, consequentemente, levando a um maior apoio financeiro e institucional 148 .

Dentro da conjuntura da Primeira Guerra Mundial, Yerkes reuniu os grandes hereditaristas da psicometria americana e submeteu cerca de 1.750 .000 membros do exército a testes mentais, o que se configurou como os primeiros estudos sobre inteligência realizados em série. Dessa maneira, um conjunto de estudos nesse sentido aflorou no ambiente científico. Um famoso psicólogo, E. G. Boring, que trabalhou com Yerkes, selecionou 160.000 casos do exército e trouxe interpretações sobre seus dados, que continuaram a influenciar a política social americana, muito depois dos testes mentais terem caído no esquecimento. Sua primeira premissa postulava que os adultos brancos americanos tinham uma capacidade intelectual muito acima da média (que eles definiam como muito acima da fronteira da debilidade mental): tal premissa converteu-se num centro de atenção de todos os eugenistas pelo mundo, que profetizaram a ruína e lamentaram o declínio da inteligência humana, provocado pela reprodução incontrolada de pobres e negros. Em sua segunda premissa, a partir dos testes aplicados, concluiu que russos, italianos e poloneses tinham debilidade mental; convicções que iam ao encontro do argumento de A. Amaral contra povos do leste europeu, italianos e da península ibérica. Por fim, sua terceira premissa deve ter influenciado a resistência de A. Amaral aos povos negros: para E. G. Boring, o negro situava-se no extremo inferior da escala. Ainda assim, ele os dividiu em três grupos, onde os negros mais claros tinham maior índice de inteligência e os mais escuros menos ${ }^{49}$. 
A partir de tais conclusões, a argumentação de A. Amaral contrária a estes povos estaria ancorada conjuntamente: na autoridade científica e no determinismo biológico dos estudos de Yerkes e dos seus pupilos, uma vez que se tratava de estudos acadêmicos de prestígio internacional para a época ${ }^{50}$ e, ao mesmo tempo, nas questões políticas e econômicas no âmbito brasileiro.

Na medida em que surgiram as primeiras tensões por melhores condições de trabalho no início do século XX, a partir do movimento que fomentou a organização operária sindical no Brasil, os líderes desse movimento eram imigrantes europeus, majoritariamente e justamente de origem italiana e ibérica: uma vez que o negro e o mestiço ainda não tinham as mesmas oportunidades no trabalho que brancos, mesmo aqueles de origem humilde. Consequentemente, esses brancos tornaram-se indesejáveis, portanto, alvo de discriminação do projeto de eugenia brasileira das elites. Passaram a ser considerados elementos antissociais, já que o projeto de formação do tipo nacional previa que, além de idealmente branco ou embranquecido, este tipo deveria ser um cordato trabalhador. Dessa maneira, explicava-se 0 viés econômico e político das ideias de A. Amaral $\frac{51}{5}$.

Por outro lado, Azevedo Amaral contrapõe que o problema eugênico da imigração não se restringe apenas à determinação de categorias étnicas desejáveis e indesejáveis, devendo-se, em algumas circunstâncias, analisar 0 imigrante de uma maneira individual:

O exame de cada caso individual de imigração é indispensável porque sem ele, mesmo quando organizássemos a nossa política imigratória, dando preferencia às populações superiores, correríamos o risco de dar entrada no país aos elementos inferiores e tarados que nelas existem. Assim, permita-nos afirmar que consideramos ser o ponto essencial na solução do problema eugênico da imigração o exame rigoroso dos casos individuais ${ }^{52}$.

Assim sendo, a seleção individual não deveria se basear mais em vigor ou força física, robustez ou saúde, como ocorreu nas políticas imigratórias do século XIX. Com o advento da indústria e da tecnologia no século XX, segundo 0 médico e jornalista, dispensava-se a imigração promíscua de contingentes de elementos inferiores, havendo o anseio de determinar quais caracteres dever-se-iam fixar na raça e aqueles outros que se deveriam eliminar. Ancorado no determinismo genético expresso na afirmação da inferioridade intelectual e moral inerentemente hereditárias, além dos argumentos dos estudos de Yerkes e de outros estudiosos da psicometria, Azevedo Amaral enfatizava que uma raça superior não é apenas aquela que goza de saúde física, mas que possui os atributos intelectuais necessários para a assimilação e ao desenvolvimento da cultura. Assim, ele exemplifica que a inteligência para lidar com máquinas e tecnologia, que seriam notadamente maiores em etnias nórdicas e alemãs, seria muito mais eficiente do que o trabalho braçal naquele momento da história brasileira ${ }^{53}$.

A avaliação da capacidade intelectual para conceder o veredito sobre a entrada de imigrantes, segundo Azevedo Amaral, poderia ser baseada em métodos rigorosamente científicos, diretos ou indiretos. Dessa maneira, A. Amaral se aproxima do anseio de Yerkes de conferir maior cientificidade a suas análises, procurando para isto, quantificar a inteligência. Apesar de reconhecer que a medição direta da capacidade intelectual seria mais satisfatória, cujo exemplo seria uma prova para avaliar a alfabetização do candidato - como ocorrido na Austrália - 0 autor compreende a impossibilidade de aplicação dos métodos diretos em razão da quantidade de indivíduos que deveriam ser avaliados. 0 ideal para ele seria métodos indiretos, como os mencionados:

(...) apresentação pelo imigrante de um titulo de habilitação profissional ou técnica, ou de um contrato de serviços no país por empresa ou pessoa de idoneidade reconhecida, bem como a posse de uma soma razoavelmente substancial, constituem outros tantos meios de formar-se um juízo sobre as qualidades mentais e morais do individuo e, portanto, da vantagem da sua admissão como elemento eugenicamente desejável $\underline{54}$. 
Nesse ponto, denotamos um desacordo com a historiografia, uma vez que Stepan relata que as leis para restringirem a entrada de imigrantes do Brasil, propostas por Amaral no Congresso em questão, se baseavam em algum tipo de teste médico, segundo o trecho original em inglês: "(...) the most controversial being a call for a national immigration law to restrict entry into Brazil to those individuals deemed eugenically "sound" on the basis of some kind of medical test" ${ }^{\prime \prime 5}$. À primeira vista, pode-se assumir que se tratava de um teste médico, afinal, era um congresso composto majoritariamente por médicos. Além disso, Azevedo Amaral utilizava de termos como métodos rigorosamente cientificos ao se referir aos testes mentais para criar critérios de seleção dos imigrantes individualmente. Contudo, baseado em uma argumentação com gritante viés de classe, o congressista ressaltava a eficácia de critérios de base social e não médica, nem psicométrica. Sustentados especificamente em critérios socioeconômicos e educacionais, ele almejava impedir a entrada de candidatos à imigração que, segundo sua concepção, poderiam ser degenerados, tarados e psicopatas, dado que seriam raras exceções indivíduos indesejáveis que obtivessem título profissional ${ }^{56}$.

Para finalizar seu trabalho, o médico e jornalista discute que a educação permitiu, nas sociedades europeias, que indivíduos dotados de melhor herança intelectual, vindos do proletariado, ascendessem de classe social. Todavia, 0 médico justifica essa a ascensão social exclusivamente a fatores mentais, segundo ele, em função de serem "melhor

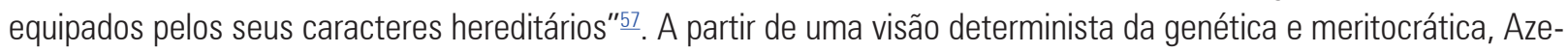
vedo Amaral menciona que as estratificações inferiores do proletariado europeu são aquelas dotadas de uma herança inferior de intelectualidade, considerando-as como mentalmente e, portanto, biologicamente inferiores. A partir disso, segundo ele, há uma verdadeira seleção social:

Vai-se dando assim um verdadeiro processo de seleção social, do qual resulta que as estratificações inferiores do proletariado europeu, as massas de trabalhadores meramente musculares se vão formando quase exclusivamente pelos indivíduos em quem o peso da fatalidade de uma herança inferior os inabilita a aproveitarem-se das vantagens que a democratização pedagógica a todos proporciona.

Em outras palavras, para o eugenista brasileiro, isso implicava na sua incredulidade na regeneração da população desfavorecida através da educação, dado que a herança genética, supostamente inferior em determinadas etnias, seria um limitador do desenvolvimento intelectual. Em muitos trechos, Azevedo Amaral expõe seu determinismo genético, por declarar que o esforço das elites em educar as massas seria improdutivo, pois a genética as condena à animalidade: "0 abnegado esforço redentor das elites, procurando levantar as massas do abatimento, a que as reduz a força gravitacional da hereditariedade, arrastando sempre para a animalidade". Assim, para o médico carioca, era inútil tentar-se a melhora da sociedade pela educação, uma vez que havia a necessidade de se repetir todo o trabalho educativo em cada geração e que seriam conquistas precárias para a civilização por não se alterar os atributos hereditários. Ainda para ele, em casos de circunstâncias perturbadoras e propensas à barbárie (as quais não exemplifica), as camadas populares, descritas como taradas pela hereditariedade selvagem, abandonariam imediatamente seu estado de civilização. Assim, ele afirma que a descendência desses grupos só foi perpetuada por sua conservação no núcleo de privilegiados hereditariamente, argumento que pode indicar uma suposta rejeição de Amaral à mestiçagem ${ }^{58}$.

Assim, o médico e jornalista enfatizava a necessidade de seleção a partir de caracteres intelectuais das elites, destilando seu desprezo em relação às camadas populares, condenadas por sua genética:

Seria insânia, diante dos resultados da pesquisa biológica a que nos referimos no começo desta tese, continuar a entreter a ilusão pueril de que o nosso ambiente pode regenerar esses infelizes condenados pela fatalidade hereditária. Com as suas taras eles serão elementos obstrutivos das engrenagens da nossa máquina econômica, fatores de perturbação social, elementos adicionais a reforçar as nossas estatísticas criminais, parasitas que viverão à custa do nosso trabalho, e, o que é mil vezes mais grave, esses indesejáveis de hoje perpetuarão na sua prole as misérias que trazem impressas no plasma germinativo e se multiplicarão pela terra brasileira como legião malfazeja de improdutivos e de rebeldes, repetindo em cada geração a tragédia em que os seus antepassados naufragaram socialmente nas suas pátrias originárias ${ }^{\frac{59}{9}}$. 
A proposta eugênica apresentada pelo congressista sustenta seus posicionamentos apresentados em suas futuras obras na década de 1930. Azevedo Amaral se caracterizava por uma visão histórica enfatizando progresso econômico e industrial, vinculando o nacionalismo ao industrialismo e ao capitalismo, desprezando nos seus trabalhos quaisquer soluções assistencialistas, de saúde pública ou educacional, inclusive negando a efetividade da democracia no Brasil|00. Na realidade, tal negação não se restringia ao pensamento eugênico de A. Amaral. Nos Estados Unidos, 0 eugenista Goddard argumentava que democracia significava selecionar os mais sábios, os mais inteligentes e os mais humanos, para que eles digam como seguir. Portanto, para ele, a democracia era um método para se chegar a uma aristocracia benévola ${ }^{61}$.

Todavia, é importante acentuarmos que o movimento eugênico brasileiro não era homogêneo, o que repercutiu numa forte resistência de alguns congressistas, à proposta de imigração de Azevedo Amaral. Além disso, outros diversos temas sobre eugenia foram motivo de confrontos de ideias, como em relação à miscigenação, os quais serão temas da próxima seção.

\section{As divergências sobre o racismo entre mendelianos brasileiros: o protagonismo de Edgard Roquette-Pinto no PCBE}

Nos registros das atas das reuniões do Congresso, um dos eugenistas que se destacou como imediatamente contrário à proposta de imigração de Azevedo Amaral foi Edgard Roquette-Pinto ${ }^{62}$. 0 antropólogo e médico foi mais conhecido como sendo um dos principais dirigentes do Museu Nacional no Rio de Janeiro durante a década de 1930, período que a instituição ganhou grande reconhecimento e destaque ${ }^{63}$. Com experiência nos campos da antropologia física e etnografia por décadas, nos quais esteve ligado ao Museu Nacional, Edgard Roquette-Pinto marcou sua trajetória científica por caracterizações etnográficas, pesquisas sobre a linguagem, a tradição e as condições sociais dos povos indígenas e sertanejos, incluindo trabalhos sobre o significado da miscigenação racial na formação da nação brasileira ${ }^{64}$. 0 mesmo se mostrou contrário às ideias racistas e elitistas, alegando que os critérios econômicos de Azevedo Amaral não eram aplicáveis, uma vez que indivíduos com posses e qualificações não viriam ao Brasil como imigrantes. Roquette-Pinto enfatizava que todo progresso obtido no Brasil até então, foi realizado por essa gente proveniente da miscigenação, taxados como inferiores por A. Amaral ${ }^{65}$.

Em seu próprio trabalho no Congresso Nota sobre os typos anthropologicos no Brasil, Roquette-Pinto já demonstra sua consciência sobre os problemas da política de povoamento do Brasil no passado, denunciando as atrocidades sobre os povos indígenas e negros, abandonando-os à indigência até sua época ${ }^{66}$. Ademais, o mesmo alerta para a necessidade de se atentar aos fenômenos sociais e à comparação histórica das proibições da entrada de negros, traçando um paralelo com a escravidão. Na década de 1920 não se aceitava, de maneira nenhuma, a escravidão: sendo assim, a proposta de proibição da entrada de negros no Brasil também poderia soar absurda no futuro ${ }^{67}$.

Outro eugenista que se destacou sendo contrário às propostas racistas foi o ginecologista Fernando de MagaIhães (1878-1944), declarando que eugenia não excluía humanidade, dado que as restrições às correntes imigratórias levavam a uma injustiça e, metaforicamente, ao suicídio, segundo ele: "Os pigmentos não excluem qualidades. Há uma injustiça, porque todo nosso passado se funda no mestiço e há um suicídio, porque todos somos mestiços e assim nos excluímos". Contudo, muitos eugenistas defendiam as ideias de Azevedo Amaral e relativizavam os argumentos contra o mesmo. 0 médico Oscar Fontenelle chama a atenção para que os contrários não utilizem de sentimentalismos, visto que o Brasil tem sofrido com o cruzamento de raças diversas. Segundo ele: "Basta para ter-se uma impressão da verdade do que acabo de afirmar, que se tome um trem e se contemple a raça brasileira" $\underline{60}$.

Sem embargo, as ideias de Azevedo Amaral, de fato, apenas ficaram no âmbito de propostas. No debate acalorado entre os grupos, foi uma das poucas postulações que não foram aprovadas em sua forma original. Sua proposta de 
política nacional de exclusão de imigração baseada na raça foi indeferida pelos participantes do congresso por 25 votos contra $17^{69}$. Apesar do racismo enraizado na sociedade brasileira da época e, por isso, refletido na ciência brasileira, leis de imigração e segregação racial, como a americana e a sul-africana, não foram aprovadas no Brasil. Segundo Stepan (1991), tal ausência pode ser explicada através da diferente visão que as elites brasileiras e americanas tinham das relações de raça: a elite branca brasileira era hábil para controlar e impedir a mobilidade social através de mecanismos informais, como as políticas de clientelismo, não necessitando de políticas públicas oficiais para controlá-las ${ }^{70}$.

Outro alvo de intensa discordância entre os eugenistas era a questão da miscigenação. Há um frequente embaraço dos cientistas brasileiros, num confronto de argumentos, os quais alguns entendiam a mistura racial como um sinal de inferioridade e decadência nacional, outros possuíam argumentos sustentando que a miscigenação poderia ter significado biológico-social considerado benéfico ${ }^{71}$.

A favor da miscigenação destacaram-se dois eugenistas, Álvaro Fróes da Fonseca (1890-1988) e novamente Roquette-Pinto, cuja formação, no caso de ambos, contemplou o contato com o culturalismo norte-americano do antropólogo antirracista Franz Boas, impedindo a eugenia brasileira de atingir níveis mais elevados de racismo. Em sua conferência intitulada Os Grandes Problemas da Antropologia, o médico e antropólogo Fróes da Fonseca evidencia que a mestiçagem não é em si causa de degradação, dado que mestiços são encontrados em diferentes graus em todas as populações do planeta e que os fatores preponderantes no adiantamento ou atraso cultural não são precisamente os de raça. Ele também cita pesquisas de E. Fischer e de Rodenvafdt, que revelavam que filhos mestiços apresentavam pequena mortalidade infantil, qualidades físicas características de uma população forte e sadia. Assim, ele se mostra consciente das ideias de hereditariedade mendelianas já discutidas no exterior. Utilizando as argumentações de $\mathrm{E}$. Fischer em seu trabalho, Fonseca informa que pesquisas científicas que antecedem o reconhecimento da aplicabilidade ao homem das leis de Mendel carecem de valor decisivo. Sobre as leis de Mendel, Fonseca esclarece: "Só o reconhecimento destas, mostrando, como se alternam, combinam, dissociam e recombinam caracteres, pode fornecer base científica ao estudo analítico de uma população mestiça. E estudos desta natureza já os temos capazes de uma resposta geral à questão"프.

Fróes da Fonseca rejeita a ideia de sangue ariano, que ele o descreve como "fantasias dos pregoeiros" e que, em meios científicos, não se deve levar à sério. 0 mesmo também ressalta a confusão feita na comparação entre os mestiços criados em condições saudáveis com aqueles rejeitados e que estão à margem da sociedade, evidenciando que, dadas as condições necessárias, poderíamos ter uma população fisicamente forte para encarar o futuro com otimismo. De forma enfática, Fróes da Fonseca critica o fazer científico baseado em discriminações infundadas:

\begin{abstract}
Infelizmente enquanto vai a ciência abrindo penosamente o seu caminho, segue-lhe os passos a constante coorte de aproveitadores do momento, dos que, à sombra do seu prestígio, fazem de hipóteses dadas como fatos, de afirmações transfiguradas em documentos, de fragmentos doutrinários torcidos e ajeitados a qualquer tese e tudo bem vestido de eloquência, a obra que se populariza porque não combate senão os preconceitos reinantes ${ }^{73}$.
\end{abstract}

Inclusive, o médico mesmo utilizava-se de argumentos baseados na história natural para defender a miscigenação, inferindo que a espécie que se estabiliza, estaciona evolutivamente e não progride. Apesar de Fonseca denotar um referencial divergente de evolução na perspectiva darwiniana - numa concepção evolutiva que caminha ao progresso biológico - por outro lado, ele demonstra apoio à miscigenação utilizando argumentos biológicos. 0 cientista encerra seu trabalho fazendo reflexões ao próprio rumo do movimento eugênico, rejeitando uma eugenia racista e homogeneizante, propondo que o movimento se atentasse às questões higiênicas e educacionais para a prevenção da proliferação de taras ${ }^{74}$.

Já em seu trabalho Nota sobre os typos anthropologicos no Brasil, Roquette-Pinto faz uma análise dos tipos antropológicos brasileiros através de seriação de caracteres de acordo com frequência, conforme se costumava praticar na biologia - 0 que assinala como 0 início da antropologia estava intrinsecamente associada à prática das ciências 
biológicas. Roquette-Pinto segrega os indivíduos brasileiros em raças: leucodermos (brancos), phaiodermos (branco miscigenado com negro), xanthodermos (branco miscigenado com índio) e melanodermos (negros) e verifica valores de índice cefálico, índice nasal, altura, força física, medidas do osso zigomático e perímetro toráxico. Em seguida, ele mostra ciência sobre os princípios mendelianos, inclusive apresentando um heredograma destacando que tipos brancos podem ter uma avó negra e esclarecendo que é um erro crer que os filhos de mulatos são sempre mulatos. Comparando seus resultados com alguns estudos realizados em diversos países, o médico e antropólogo chega à conclusão de que, pelas análises matemáticas de seus dados antropométricos, não existe a fusão de raças numa forma definida. Consequentemente, os mulatos formam um grupo pouco homogêneo e nenhum dos critérios analisados permite considera-los como tipos involuídos ${ }^{75}$. Somando-se a isso, ele argumenta sobre a importância não só de fatores biológicos na análise dos cruzamentos, mas também de fatores sociais.

Para exemplificar, ele cita os nordestinos do estado do Ceará, onde não houve imigração europeia italiana ou alemã e a miscigenação se deu por cruzamentos entre leucodermos (portugueses) e xantodermos (mestiços de povos indígenas) (Figura 2).

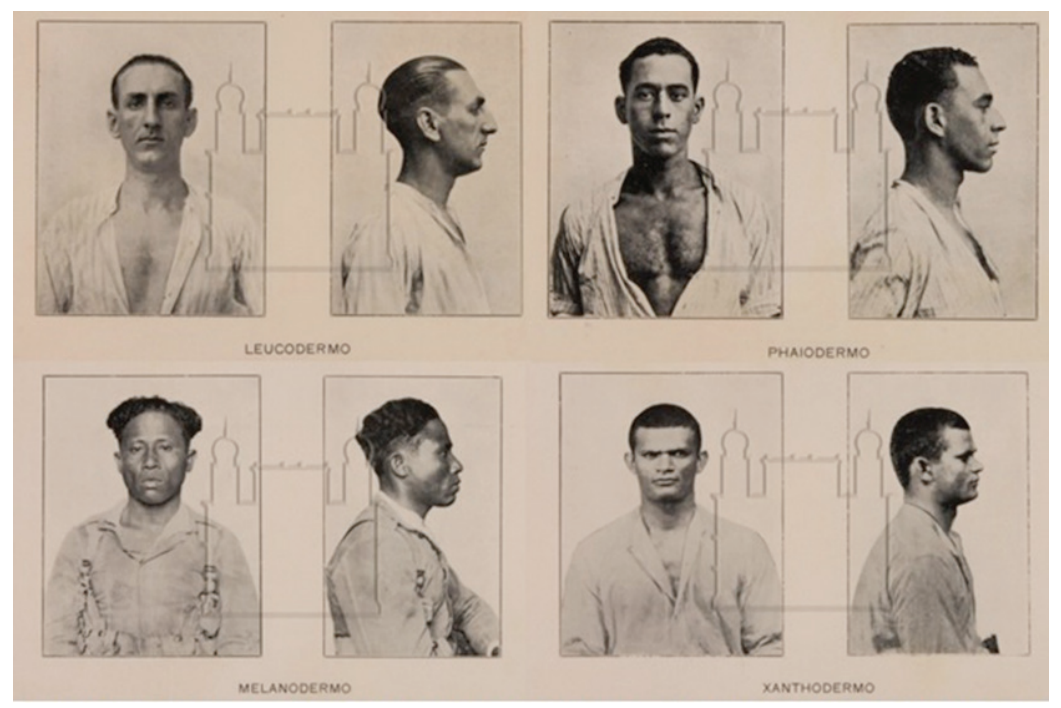

Figura 2: As raças brasileiras segundo o trabalho de Roquette-Pinto publicado no Primeiro Congresso Brasileiro de Eugenia. Fonte: PCBE (1929)

Apesar das imensas dificuldades sociais e geográficas, o cientista empodera os nordestinos, argumentando que 0 estado é numeroso, com indivíduos de resistência física e firmeza moral7 ${ }^{76}$. Contra argumentando as ideias de A. Amaral sobre a capacidade intelectual - apesar de não o citar em seu trabalho - Roquette-Pinto nega que mestiços sejam inferiores intelectualmente aos brancos, argumentando que a diferença é, sobretudo, uma questão de educação:

Os mestiços que recebem instrução técnica (mecânicos, operários especializados etc) são tão bons quanto os europeus. Os que não conhecem senão os mestiços degradados das grandes cidades, onde o meio cosmopolita corrompe facilmente aqueles que a educação não fortifica, e os que só conhecem os mestiços opilados ou impaludados do interior, não podem fazer ideia da perseverança, da firmeza, da dedicação de que dá prova o do hinterland, cuja sobriedade é proverbial ${ }^{77}$.

Na conclusão de seu trabalho, o médico denuncia os discursos que confundem "raça" com "nação". Apesar de reconhecer a quantidade de doentes e deficientes, ele enfatiza que essa causa não é racial, mas, uma questão 
de política sanitária e educativa, o que exige que o homem seja educado e, não, substituído ${ }^{78}$. Tal comportamento é evidenciado na década de 1930, uma vez que Roquette-Pinto assinou - junto com outros importantes nomes da ciência e da literatura, como Gilberto Freyre - o "Manifesto dos Intelectuais Brasileiros contra o Racismo", representando uma das maiores manifestações públicas do antirracismo na história da ciência brasileira ${ }^{79}$.

Portanto, Roquette-Pinto e outros eugenistas alertavam que as principais causas da degeneração racial não eram a mestiçagem e o clima. Assim como Souza (2008) descreve, a partir do desenvolvimento das pesquisas bacteriológicas e sobre patologia de doenças tropicais, a ciência demonstrava que 0 atraso do país estaria relacionado às doenças e à falta de saneamento. Através de uma interpretação que valorizava os problemas sociais, a ciência brasileira abriria caminho para uma nova interpretação médico-sanitarista, diminuindo a culpabilização racial ${ }^{80}$.

É interessante notar a diferença de interpretação sobre a hereditariedade, em autores que se aproximavam da visão mendeliana. Segundo Stepan (2008), alguns médicos declaradamente mendelianos, como Roquette-Pinto e Fróes da Fonseca, exibiam, além de um grande senso crítico quanto às ideias de hereditariedade, um engajamento maior em relação às ciências sociais, não por serem mendelianos, mas por ambos terem sido médicos que tiveram mais contato com as ciências humanas, especialmente a antropologia americana de Franz Boas르. Contudo, Souza (2016) discorda de Stepan, ao atribuir a atitude antirracista de Roquette-Pinto a outros fatores, como à leitura de geneticistas e antropólogos físicos mendelianos, sobretudo nos EUA e na Alemanha, por parte do antropólogo ${ }^{82}$. Em todo caso, Roquette-Pinto e Fróes da Fonseca se engajaram no Congresso ao denunciarem os vieses nacionalistas e racistas em propostas eugênicas da época.

0 maior porta-voz das ideias mendelianas, do ponto de vista epistêmico, foi André Dreyfus (1897-1952), à época, era médico da Faculdade de Medicina de São Paulo e, atualmente, nomeia o Edifício do Departamento de Genética e Biologia Evolutiva da Universidade de São Paulo. Em sua conferência no PCBE, intitulada 0 estado actual do problema de hereditariedade, em vários momentos ressalta o mérito dos estudos de Mendel, numa argumentação quase hagiográfica, apontando sua genialidade conjuntamente a dos cientistas que reutilizaram seus estudos, como De Vries, Correns e Tschermak. Por outro lado, Dreyfus não detalha as ideias sobre miscigenação. Mais preocupado em discutir o conteúdo epistêmico biológico, Dreyfus cita Charles Davenport (1866-1944), um dos líderes do movimento eugênico americano, para evidenciar a aplicabilidade das leis de Mendel no âmbito humano. Utilizando o termo polimeria, Davenport explicava que a herança da cor de pele em humanos envolvia mais de um fator para a herança genética em termos da linguagem mendeliana ${ }^{83}$. Com essa explicação, Dreyfus acabava discordando dos próprios exemplos mendelianos de Roquette-Pinto, que consideravam a determinação da cor de pele comportando-se exclusivamente através da primeira lei de Mendel. Segundo Souza (2016), Edgard Roquette-Pinto alegava a ideia de imutabilidade dos caracteres hereditários, considerando que as condições ambientais não poderiam intervir nos fatores hereditários ${ }^{84}$. Dessa maneira, o antropólogo também permeava em seu discurso o mesmo determinismo genético presente no trabalho de Azevedo Amaral.

No seu trabalho no Congresso, Dreyfus previa o entendimento da eugenia numa perspectiva mendeliana sobre as vantagens e desvantagens da consanguinidade, verificando quais características seriam recessivas ou dominantes, tentando impedir características indesejáveis - se limitando a apontar apenas doenças - e propunha que a eugenia ganhasse um viés mais científico do que estaria se encaminhando. 0 cientista tentou se ater exclusivamente no ponto de vista biológico, chegando a citar que "não nos interessa aqui o ponto de vista ético que cada qual resolverá como quiser"

Por fim, é preciso relativizar que apesar de Roquette-Pinto ser um defensor da miscigenação e convicto da mesma capacidade intelectual entre as raças, o médico e antropólogo diferenciava moralmente os negros dos brancos, colocando os primeiros como dotados de uma fraqueza: a emotividade exagerada, segundo ele, uma ótima condição para 0 surto dos estados passionais ${ }^{\frac{86}{}}$. Entretanto, não devemos desconectar Roquette-Pinto anacronicamente da cultura de seu tempo, numa atitude de analfabetismo histórico. Frente às posturas da época, devemos reconhecê-lo, ainda assim, como um dos principais militantes contra o racismo na ciência brasileira. 


\section{Considerações finais}

Uma das contribuições desse trabalho é questionar o ideário geral de que os eugenistas brasileiros negligenciavam assuntos como genética, que representava sua argumentação biológica, acreditando serem menos abordados em seus trabalhos ${ }^{87}$. Tal ideário pode ser exemplificado pela impressão que o eugenista inglês K. E. Trounson demonstrou ao ler alguns artigos de eugenistas brasileiros em 1931. Sua opinião, que foi publicado na Revista Eugenics Review e editado pela Eugenics Society de Londres, concluiu que a eugenia brasileira se caracterizava por uma abordagem mais sociológica que biológica, diferentemente de outros movimentos, como sua vertente britânica ${ }^{88}$. Nossa pesquisa esclarece que a então recente área da genética estava presente nas discussões da maior manifestação da eugenia no Brasil, o PCBE, inclusive em trabalhos classificados no âmbito sociológico pelos próprios autores, como é o caso de Azevedo Amaral ${ }^{89}$, que aborda, em seu estudo, referências importantes de vários autores da genética e de pesquisas das ciências biológicas. Portanto, nosso trabalho contribui mais apropriadamente para o entendimento da argumentação biológica utilizada no movimento eugênico brasileiro - a qual era essencial para a compreensão do movimento - e como ela se relacionava a outros variados fatores socioculturais, como racismo, nacionalismo e políticas públicas, a exemplo de medidas para a seleção imigratória e educação.

Nesse âmbito, discutimos como as ideias de Azevedo Amaral utilizavam argumentos de base biológica, conectadas ao determinismo genético para fatores intelectuais e morais, as ideias poligenistas e aos estudos da psicometria: 0 que é pouco esclarecido na historiografia sobre Azevedo Amaral até o momento. As ideias de proibição da entrada de imigrantes não-brancos do autor refletiam a crença de aproximação entre os conceitos "raça" e "nação", muito comum nos discursos autoritários da época. Além disso, em sua proposta de seleção de entrada dos imigrantes no Brasil, ele utilizava-se de estudos científicos de Yerkes - por sua alta evidência e prestígio na época - e do termo métodos rigorosamente científicos, buscando elevar a credibilidade de seus argumentos, utilizando-se de um determinismo biológico e de estudos quantitativos. Seu discurso era caracterizado por uma inferiorização de negros, indígenas e das camadas populares, munindo-se com argumentação biológica determinista, imersa em um autoritarismo de natureza econômica que negava a democratização pedagógica. Nesse sentido, nossa análise documental do PCBE sustenta posicionamentos recentes de historiadores da eugenia, como trazidos por Souza (2016) $)^{90}$. Assim como para 0 autor, consideramos que associar a eugenia latino-americana a um modelo mais suave de pensamento eugênico, como feito por autores como Stepan (1991), pode ser problemático ao ocultar a adesão de pesquisadores brasileiros, como Azevedo Amaral, ao racismo científico e aos programas radicais de intervenção eugênica, como propostas de segregação racial.

Por outro lado, Roquette-Pinto caracterizou-se por romper estereótipos sobre os eugenistas: 0 cientista discorda de Amaral e enfatizava que o povo não deveria ser substituído e, sim, educado. Assim, o cientista, contemplado pela proposta antirracista de Fróes da Fonseca, criticou as ideias negativas sobre a miscigenação, empoderou negros, indígenas e nordestinos, inclusive com evidências de seus estudos antropométricos. Amparado pela discussão epistêmica de André Dreyfus, ciente das ideias de hereditariedade mais recentes discutidas na Europa, Roquette-Pinto se utilizou do mendelismo de forma distinta e condenou o racismo científico criticamente, apesar de utilizar-se de um determinismo genético com seus heredogramas sobre cor de pele em humanos.

Enfatizamos aqui uma importante questão: a controvérsia e o desacordo científico, característico da ciência. Por mais que Azevedo Amaral e Roquette-Pinto se aproximavam sobre a proposta mendeliana no PCBE e, ao mesmo tempo, refletiam igualmente um determinismo genético, os mesmos se distanciavam, consideravelmente, em como tais conceitos científicos poderiam estar conectados às ideias de miscigenação ou serem aplicados na eugenia como medidas de políticas públicas. Portanto, assim como levantado por historiadores da ciência importantes nos estudos eugênicos, como Jerry Dávila, a eugenia possibilita formar conexões e diálogos com uma variedade de disciplinas e campos de investigação, associando ciências humanas e naturais. Tal característica do movimento eugênico pode ser explicada pela diversidade de teorias para explicar a eugenia e de como esta seria praticada ${ }^{91}$. Dessa maneira, a partir das reflexões discutidas nessa pesquisa, fica-se evidenciada a complexidade da eugenia como movimento científico e social brasileiro. 


\section{Notas e Referências Bibliográficas}

Anderson Ricardo Carlos é biólogo pela UNESP Botucatu, com período sanduíche na Radboud University (Holanda). É mestre pelo Programa de Pós-Graduação em Ensino e História das Ciências e da Matemática da UFABC, no qual defendeu a dissertação intitulada "Problematizações Históricas do Primeiro Congresso Brasileiro de Eugenia para o Ensino de Biologia", cuja pesquisa deu origem a esse artigo.Email: anderson.rc@hotmail.com

Fernanda Franzolin é pedagoga, bióloga, mestre e doutora pela USP, tendo sido pesquisadora visitante na Western Michigan University, EUA, na área de Ensino de Genética. Atualmente é Professora Adjunta do Centro de Ciências Naturais e Humanas da UFABC, onde atua como coordenadora do curso de Licenciatura em Ciências Biológicas. Email: fernanda.franzolin@ufabc.edu.br

Márcia Helena Alvim é historiadora, mestre e doutora pela UNICAMP, na área de História das Ciências. Atualmente é Professora Associada no Centro de Ciências Naturais e Humanas da UFABC, onde atua como coordenadora de Licenciatura em Ciências Humanas. Foi coordenadora do Programa de Pós-Graduação em Ensino e História das Ciências e da Matemática. Email: marcia.alvim@ufabc.edu.br

Agradecemos pelo apoio financeiro da CAPES através da bolsa de demanda social, custeando a pesquisa em questão.

1 SCHWARCZ, Lilia Moritz. 0 Espetáculo das Raças: Cientistas, Instituições e Questão Racial no Brasil 1870-1930. 14. ed. São Paulo: Companhia das Letras, 1993.

2 Idem, p.63-65

3 BROCA, Paul. On the phenomena of hybridity in the genus homo. London: C. Carter Blake, 1864.

4 SILVA, Eliana Gesteira da; FONSECA, Alexandre Brasil. Ciência, estética e raça: observando imagens e textos no periódico 0 Brasil Médico, $1928-1945$. História, Ciências, Saúde - Manguinhos, Rio de -Janeiro, v. 20, 2013, p. 1287-1313.

5 SCHWARCZ, 1993, op. cit.

6 STEPAN, Nancy. Leys. The Hour of Eugenics: Race, Gender and Nation in Latin America. 1. ed. Ithaca: Cornell University Press, 1991.

7 SOUZA, Valdir Sebastião. Por uma nação eugênica: higiene, raça e identidade nacional no movimento eugênico brasileiro dos anos 1910 e 1920 . Revista Brasileira de História da Ciência, Rio de Janeiro, v. 1, n. 2, jul-dez. 2008, p. 146-166.

8 STEPAN, 1991, op. cit

9 BIZZO, Nélio Marco Vicenzo. Meninos do Brasil: ideias de reprodução, eugenia e cidadania na escola. 1994. Tese (Livre-Docência) - Faculdade de Educação, Universidade de São Paulo, São Paulo, 1994.

10 STEFANO, Waldir. Octavio Domingues: Concepções sobre miscigenação no contexto eugênico. Temas \& Matizes, n. 15, 2009, p. 42-54.

110 higienismo-sanitarismo se consolidou como uma das bases da doutrina médica da época. Nele, o sanitarista se configurava como o médico responsáve pelos grandes projetos de saúde pública e o higienista - mais urgente no Brasil - se vinculava diretamente às pesquisas e às atuações médicas mais individualizadas, cujas funções de ambos, na prática, apareciam de modo conjunto.

12 MATOS, Maria Isilda. Em Nome do Engrandecimento da Nação: Representações de Gênero no Discurso Médico - São Paulo 1890-1930. Diálogos, v. 4, p. 77-92, 2000

130 tenentismo explicitou um programa de traços essenciais baseados no estatismo, autoritarismo e elitismo, fatores que se conectavam, em parte, às bases do surgimento do movimento higienista-sanitarista. Dessa maneira, ambos os movimentos sanitarista-higienista e tenentista estavam presentes no Brasil na conjuntura sociopolítica, quando os movimentos eugênicos atingiram seu ápice de atenção no século XX. No movimento eugênico brasileiro, 0 exército se concentrava no estímulo ao desenvolvimento da educação cívica e física nas escolas. Almejavam criar a "mística da criança-soldado", por sua vez, com intuito de construção da unidade nacional.

14 VILHENA, Cynthia Pereira Sousa. Práticas Eugênicas, Medicina Social e Brasil Republicano. Revista da Faculdade de Educação. v.19, n.1, 1993, p. $79-82$.

15 FORJAZ, Maria Cecília Spina. Atlas Histórico do Brasil. Fundação Getúlio Vargas. Disponível em: <https://atlas.fgv.br/verbetes/tenentismo> Acesso em 06 jan. 2019.

16 SOUZA, Vanderlei Sebastião. Arquivo de Antropologia Física do Museu Nacional: fontes para a história da eugenia no Brasil. História, Ciências, Saúde Manguinhos, Rio de Janeiro, v. 16, n. 3, 2009, p. 763-777.

17 STEPAN, 1991, op. cit, p. 54, tradução do autor

18 Idem, p. 104, 169

19 Idem, p. 157

20 SILVA, FONSECA, 2013, op. cit, p. 1290

21 SOUZA, 2009, op. cit, p. 765

22 GERALDO, Endrica. 0 "perigo alienígena": política imigratória e pensamento racial no Governo Vargas (1930-1945). Tese (Doutorado), Instituto de Filosofia e Ciências Humanas, Universidade Estadual de Campinas, Campinas, 2007.

23 STEPAN, 1991, op. cit, p. 124-127

24 AMARAL, Antonio José Azevedo. 0 problema eugênico da Imigração. In: PRIMEIRO CONGRESSO BRASILEIRO DE EUGENIA, s.n., 1929, Rio de Janeiro. Anais do Primeiro Congresso Brasileiro de Eugenia. Rio de Janeiro: Academia Nacional de Medicina, 1929. v.1, p. 327-342.

25 ACADEMIA NACIONAL DE MEDICINA. Anfiteatro de Química da Faculdade de Medicina do Rio de Janeiro. Actas do Primeiro Congresso Brasileiro de Eugenia. 1929, de 01 a 07 de julho de 1929, p. 16. Disponível em: <http://docvirt.com/docreader.net/DocReader.aspx?bib=acebibcoc_r\&pagfis=9788> . Acesso em: 17 mai. 2018 
AMARAL, 1929, op. cit, p. 330

BIZZO, 1994, op. cit.

SAES, Guillaume Azevedo Marques de. Uma Análise do Pensamento de Azevedo Amaral com base em suas obras: o Brasil na crise atual e 0 Estado autoritário e a realidade do Brasil. Territórios e Fronteiras, v. 1, n. 1, 2008.

AMARAL, 1929, op. cit, p. 333

Idem, p. 330

Idem, p. 338

HOLMES, Samuel. The Trend of The Race. New York: Harcourt, Brace and Company, 1921, p. 18.

POPENOE, Paul; JOHNSON, Roswell Hill. Applied Eugenics. New York: The MacMillan Company. 1918, p. 37.

AMARAL, 1929, op. cit, p. 333-334

SCHWARCZ, 1993, op. cit, p. 302

STEPAN, 1991, op. cit, p. 127

ANDRADE, Rosany Espírito Santo. Azevedo Amaral no Primeiro Congresso Brasileiro de Eugenia: a imigração para purgar as "degenerescências" do povo brasileiro (Rio de Janeiro - 1929). UNIABEU, v. 6, n. 14, 2013, p. 51.

GOULD, Stephen Jay. A Falsa Medida do Homem. São Paulo: Editora WMF Martins Fonte. 3 ed. 2014, p. 165.

SCHWARCZ, 1993, op. cit, p. 302-304

MOREIRA, Juliano. A seleção individual de imigrantes no programa da hygiene mental. Archivos Brasileiros de Higiene Mental, Rio de Janeiro, v. 1, n. 1, 1925 , p. 109-115

STEPAN, 1991, op. cit, p. 166.

EL-DINE, Lorenna Ribeiro Zem. Eugenia e seleção imigratória: notas sobre o debate entre Alfredo Ellis Junior, Oliveira Vianna e Menotti Del Picchia, 1926. História, Ciências, Saúde - Manguinhos, Rio de Janeiro, v. 23, 2016, p. 243-252.

AMARAL, 1929, op. cit, p. 334

MOREIRA, 1925, op. cit

AMARAL, 1929, op. cit, p. 335-336

GOULD, 2014, op. cit

AMARAL, 1929, op. cit, p. 336

GOULD, 2014, op. cit, p. 200-201

49 Idem, p. 204-207

50 Idem, p. 200-204

51 SARMIENTO, Erica. A "não democracia" dos excluídos: alguns pontos da política migratória brasileira. Logos: Comunicação \& Universidade, v. 14, n. 27, 2007.

52 AMARAL, 1929, op. cit, p. 337

53 Idem, p. 332

$54 \quad$ Idem, p. 337

55 STEPAN, 1991, op. cit, p. 54

56 AMARAL, 1929, op. cit, p. 335-338

$57 \quad$ Idem, p. 338

$58 \quad$ Idem, p. 330-331

$59 \quad$ Idem, p. 338-339

60 SAES, 2008, op. cit

61 GOULD, 2014, op. cit, p. 166

62 ACTAS, 1929, op. cit

63 SCHWARCZ, 1993, op. cit, p. 125

64 SOUZA, Vanderlei Sebastião. Em busca do Brasil: Edgard Roquette-Pinto e o retrato antropológico brasileiro (1905-1935). Tese (Doutorado em História das Ciências e da Saúde) - Casa de Oswaldo Cruz, Fio Cruz, Rio de Janeiro, 2011.

65 ACTAS, 1929, op. cit

66 ROQUETTE-PINTO, Edgard. Nota sobre os typos anthropologicos no Brasil. In: Primeiro Congresso Brasileiro de Eugenia, S.N., 1929, Rio De Janeiro. Anais do Primeiro Congresso Brasileiro de Eugenia. Rio de Janeiro: Academia Nacional de Medicina, 1929. v.1, p. 123.

67 ACTAS, 1929, op. cit, p. 18-19

68 Idem, p. 20

$69 \quad$ Idem, p. 21

70 STEPAN, 1991, op. cit

71 Idem, p. 160 
FONSECA, Froés da. Os Grandes Problemas da Antropologia. In: Primeiro Congresso Brasileiro de Eugenia, s.n., 1929, Rio de Janeiro. Anais do Primeiro Congresso Brasileiro de Eugenia. Rio de Janeiro: Academia Nacional de Medicina, 1929. v.1, p. 76.

73 Idem, p. 78

74 Idem, p. 79-80

75 ROQUETTE-PINTO, 1929, op. cit, p. 124-129

$76 \quad$ Idem, p. 136-137

$77 \quad$ Idem, p. 137

78 Idem, p. 141-145

79 STEPAN, 1991, op. cit, p. 169

80 SOUZA, 2008, op. cit.

81 STEPAN, 1991, op. cit.

82 SOUZA, 2011, op. cit.

83 DREYFUS, André. 0 estado actual do problema de hereditariedade. In: Primeiro Congresso Brasileiro de Eugenia, s.n., 1929, Rio de Janeiro. Anais do Primeiro Congresso Brasileiro de Eugenia. Rio de Janeiro: Academia Nacional de Medicina, 1929. v.1, p. 87-98.

84 SOUZA, Vanderlei Sebastião. A eugenia brasileira e suas conexões internacionais: uma análise a partir das controvérsias entre Renato Kehl e Edgard Roquette-Pinto. História, Ciências, Saúde - Manguinhos, Rio de Janeiro, v. 23, n. 1, 2016, p. 93-110.

85 DREYFUS, 1929, op. cit, p. 96.

86 ROQUETTE-PINTO, 1929, op. cit, p. 138.

87 SOUZA, 2008, op. cit.

88 TROUNSON, K. E. The Literature Review. Eugenics Review, v. 3, n.23, oct. 1931, p. 236-237.

89 AMARAL, 1929, op. cit, p. 330.

90 SOUZA, 2016, op.cit, p. 108

91 CARVALHO, L. D; CORRÊA, I. N. C. Eugenia e educação no Brasil do século XX: entrevista com Jerry Dávila. História, Ciências, Saúde - Manguinhos, Rio de Janeiro, v. 23, 2016, p. 227-233.

[Artigo recebido em Outubro de 2019. Aceito para publicação em dezembro de 2019] 